\section{vivienda unifamiliar en Seattle}

HAROLD J. NESLAND, arquitecto

\section{simopsis}

Las distintas dependencias que componen esta vivienda unifamiliar están agrupadas en diferentes niveles, forma en que ha sido aprovechada la topografía del terreno, permitiendo crear una serie de áreas para aparcamiento, patios cubiertos, acceso a la playa para las embarcaciones, espacios para las actividades acuaticas y cobertizo para los botes. Las areas de «vivir» han sido construidas en un nivel superior al de la zona de entrada, ocupando los dormitorios la parte más elevada de la edificacion. Destaca esta vivienda unifamiliar por su doble integracion en los dos tipos de paisaje circundantes -montaña y playa-, por la elegante sencillez de sus línea

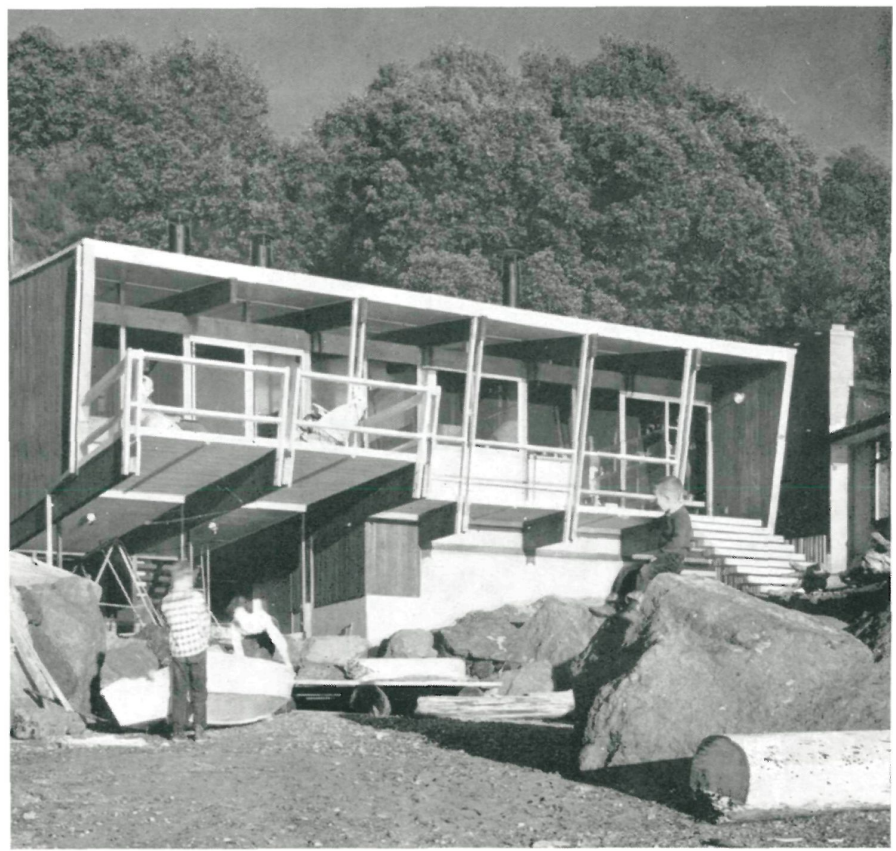

$161 \cdot 116$

Una amplia vista panorámica posterior de Puget Sound y de las montañas Olimpic, acentúa el carácter de casa-refugio que ofrece esta villa, emplazada a orillas de la playa.

Las distintas dependencias que la componen están organizadas en diferentes niveles, y se ha aprovechado además la topografía del terreno para crear una serie de: áreas de aparcamiento, patios cubiertos, un acceso a la playa para las embarcaciones, espacios para las actividades propias de la playa-deportes acuáticos-, y un cobertizo para los botes.

La entrada principal al edificio se realiza por el ala de la edificación que da a la carretera de acceso, y está al mismo nivel que los locales dedicados a trabajos de entretenimiento, talleres y almacén. Una escalera conduce al cobertizo de las embarcaciones y a la playa.

Las áreas de "vivir" han sido construidas en un nivel superior al de la entrada-entreplanta-, y los dormitorios ocupan la zona más elevada de la edificación.
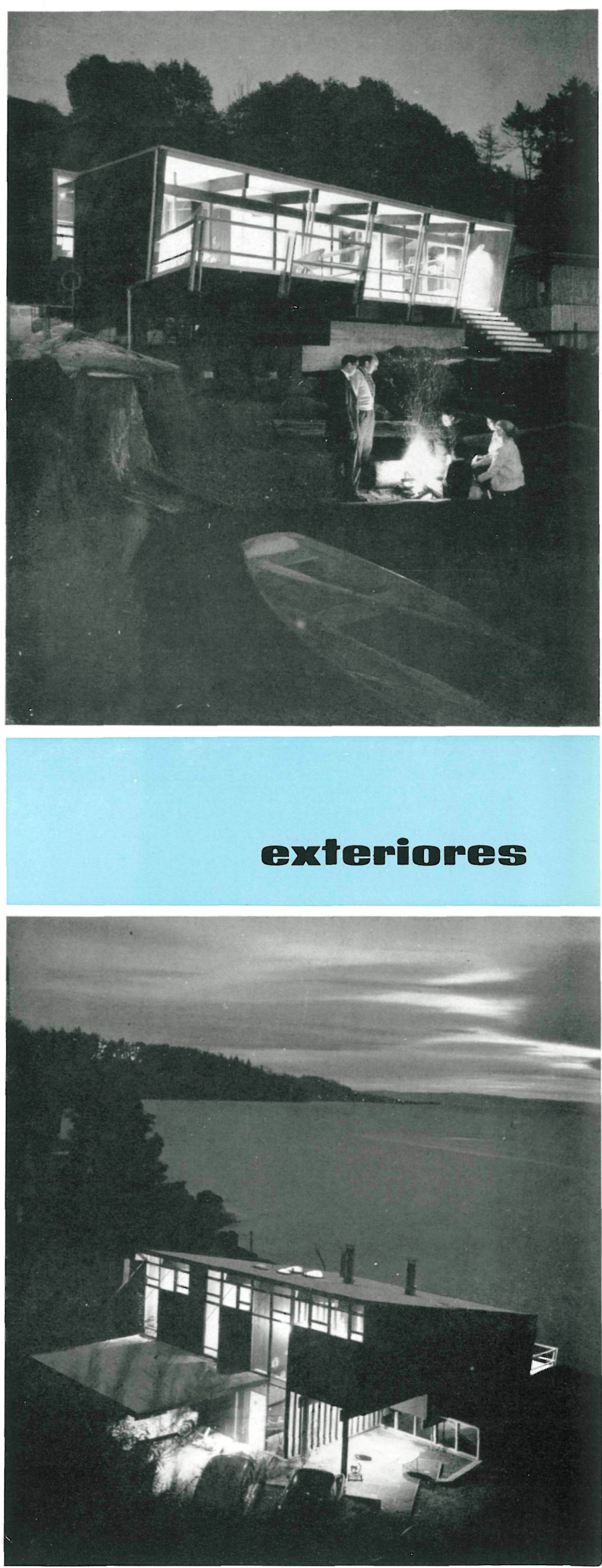


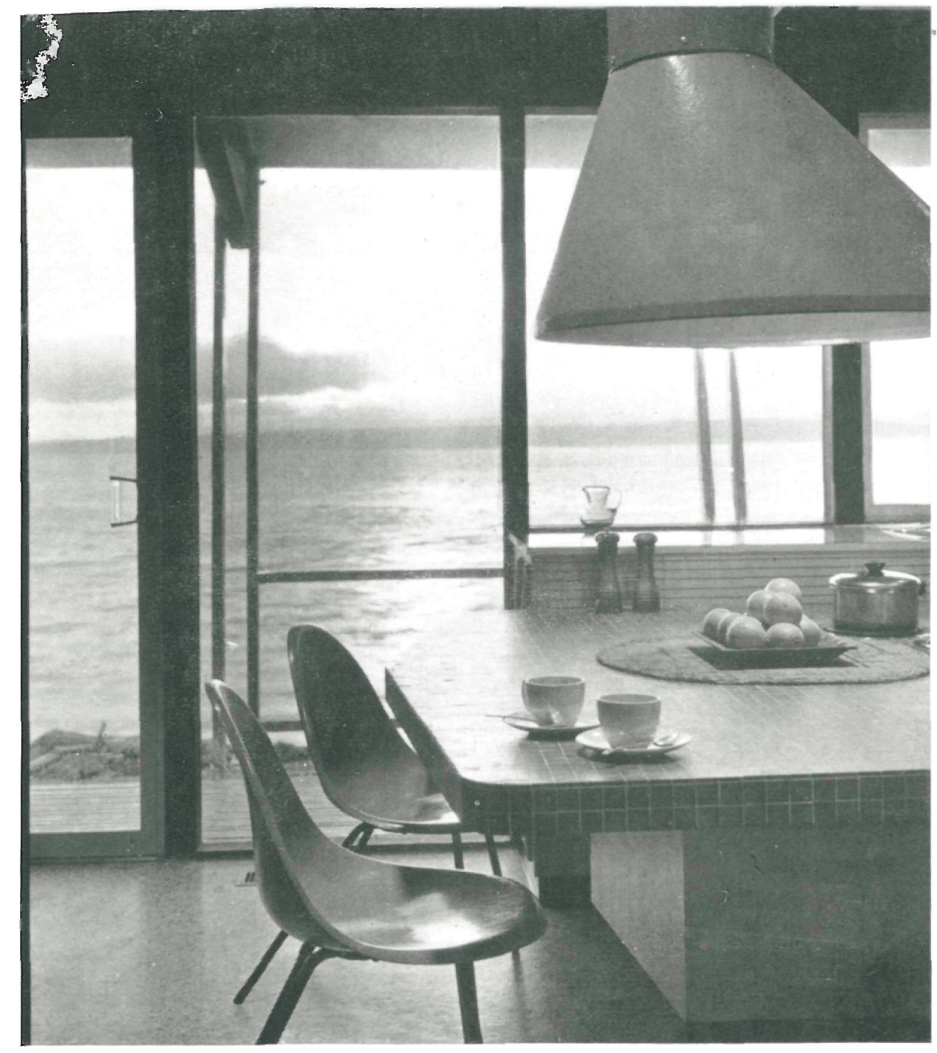

(10) lamita

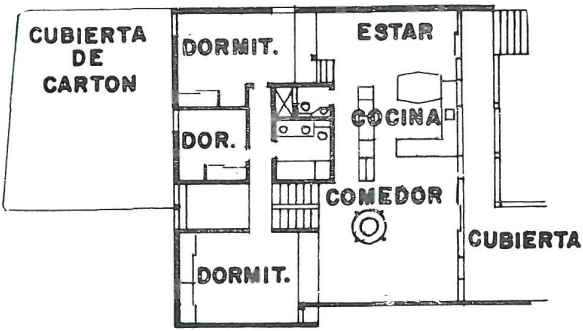

La estructura ha sido realizada a base de soportes y vigas, de madera de cedro en el exterior.

Con objeto de evitar obstáculos en una zona de espacio limitado para la maniobra de vehículos, la cubierta del cobertizo sale en voladizo del cuerpo del edificio.

El vestíbulo tiene una altura equivalente a la de dos pisos, y está separado del patio adyacente y del dormitorio principal por una mampara de plástico.

Las características fundamentales de esta vivienda unifamiliar son: su doble integración en los dos tipos de paisaje circundantes-montaña y playa-, por la elegante sencillez de sus iíneas arquitectónicas y su logrado carácter de casa-refugio.
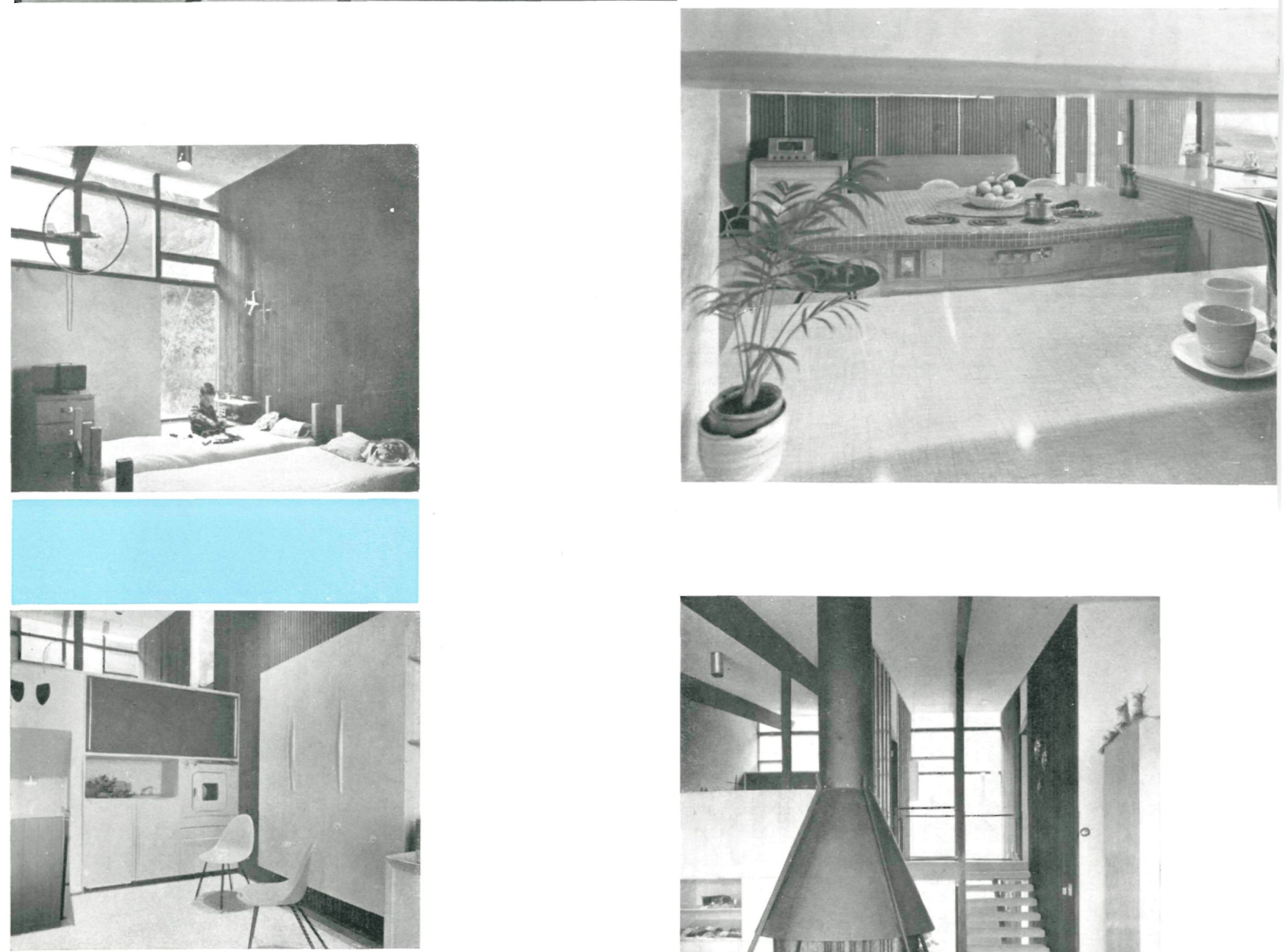

\section{interiores}

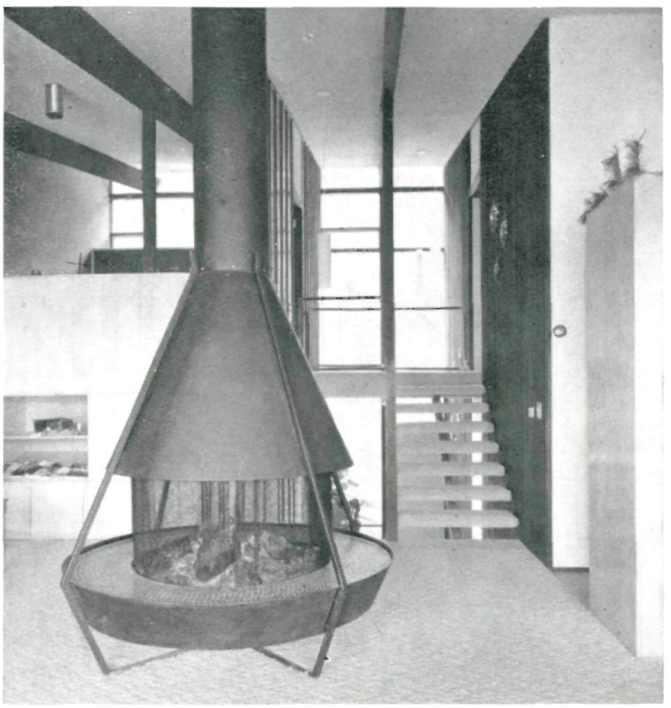




\section{Une Villa ต้ Seathe}

Harold J. Nesland, architecte.

Las différentes dépendances qui composent cette villa sont groupées sur des niveaux différents. La topographie du terrain a été utilisée pour créer una série d'emplacements pour le stationnement des voitures, cours couvertes, accès à la plage, aux embarcations, hangar pour celles-ci et espace pour les activités aquatiques.

Les surfaces de «séjour» ont été aménagées sur un niveau supérieur à celui de la zone d'entrée, les chambres à coucher occupant la partie la plus élevée du bâtiment.

Cette villa est remarquable pour sa double intégration dans les deux types de paysage environnants-montagne et plage-, pour la simplicité élégante de ses lignes architecturales et son parfait caractère de maison-refuge.

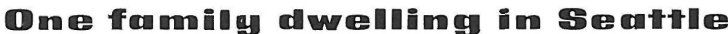

Harold J. Nesland, architect.

The house extends over several levels, following the uneven topography of the ground. This has faciliated the provision of several parking areas, covered patios, an access to the beach and storing space for boats, and for other sporting utensils.

The living zone is on a higher level than the entrance, and the bedrooms are at the highest part of the building.

This building seeks to integrate the two types of landscape which come together at its location: the beach and the mountains. Its lines are simple, yet distinguished, and it has the air of a place of comfortable refuge from the intensity of modern life.

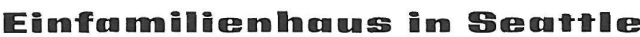

Harold J. Nesland, Architekt.

Die einzelnen Wohnteile dieses Einfamilienhauses sind auf Grund der topographischen Bedingungen des Grundstückes in verschiedenen Ebenen angeordnet, wodurch es möglich war, eine Reihe von Flächen für Parkplatz, offenen Innenhof, Zugang zum Strand und Bootssteg, Raum für Wassersport und einen Schuppen für die Boote zu schaffen.

Der Wohnteil wurde in einer Ebene über der des Einganges errichtet und die Schlafräume liegen im aller obersten Teil des Gebäudes.

Dieses Einfamilienhaus hebt sich durch seine gute Eingliederung in zwei Typen von Landschaft-Gebirge und Strand-, die elegante Einfachheit seiner architektonischen Linien und seinen Charakter als Zufluchtsort hervor. 